\title{
LANGUAGE CONTACT AND DELIBERATE CHANGE
}

\author{
Sarah G. Thomason \\ University of Michigan
}

\section{Introduction}

Historical linguists have always known that some linguistic changes result from deliberate, conscious actions by speakers. ${ }^{1}$ But the general assumption has been that such changes are relatively trivial, confined mainly to the invention or borrowing of new words, changes in lexical semantics, and the adoption of a few structural features from a prestige dialect. The goal of this paper is to show that adult speakers can and do make deliberate choices that bring about nontrivial lexical and structural linguistic change; I also discuss some of the implications of the most extreme examples for historical linguistic methodology. Although such processes are not confined to contact-induced change, the focus here is on processes motivated at least in part by language contact. The particular categories that I'll focus on are correspondence rules applied in lexical borrowing, deliberate non-change, and deliberate structural change. Perhaps the most important lesson to be learned from examples of deliberate change and deliberate non-change is that efforts to develop deterministic predictive theories of contact-induced change - either by setting theoretical limits on its extent or by predicting specific outcomes under specific linguistic and/or social conditions - are doomed; but I won't explore this point in detail in the present paper (see Thomason 2000 for discussion of the general issue).

Finally, I will argue that these linguistic events do not spell disaster for standard historical linguistic methodology, in spite of the fact that the standard methods largely rely on the assumption that language change is not subject to speakers' conscious manipulation. It is important to emphasize that even the most dramatic examples of deliberate change do not provide support either for those who argue that speakers cannot deliberately change their language enough to disrupt the

\footnotetext{
${ }^{1}$ This is a revised version of a paper that was originally presented as the Collitz Lecture in July 1999 at the LSA Linguistic Institute at the University of Illinois at Urbana-Champaign, and of a paper on the same general topic that was presented as a plenary address to the Sixteenth International Conference on Historical Linguistics at the University of Copenhagen in August 2003. I am very grateful to members of those two audiences who provided useful comments and further examples, and to other friends and colleagues who also gave me relevant examples. Thanks too to Rich Thomason for helping me understand some of the broader theoretical issues raised by the phenomena under discussion. But of course I alone am responsible for any gaps and errors that remain in the paper.
} 
application of the standard methods or for those who argue that the standard methods don't work and should therefore be abandoned.

Before beginning with a brief background discussion of the significance of the central methodology of historical linguistics, I will set the stage by giving my definition of 'contactinduced change': a particular linguistic change is caused at least in part by language (or dialect) contact if it would have been less likely to occur outside a particular contact situation. This definition includes interference of all kinds - that is, changes in which forms or structures or both are transferred from one language to another - but also changes that distance one language or dialect from another (typically, maybe always, when the two speech forms are very closely related), changes other than borrowing that occur during a process of language death (specifically, attrition), and changes that are set off by an instance of interference but then proceed via internally-motivated processes. This definition is thus quite broad (see e.g. Thomason 2001: 61-63 for further discussion).

\section{Historical linguistic methodology: the Comparative Method}

Before we consider deliberate changes, a few background comments on the importance of the historical linguist's standard methodology are in order, for the benefit of readers who haven't worked extensively with it: it is difficult to understand why a threat to the methodology would be a matter of concern without understanding the vital importance of the Comparative Method, in particular, to the field of historical linguistics. The Comparative Method is by far the most powerful tool in the historical linguist's toolbox. It dates from the 1870s in essentially its modern form, though of course we know much more about the mechanics and results of language change now than we did a hundred years ago. Because it enables us to reconstruct sizable portions of protolanguage lexicon, phonology, and morphology, and to a lesser extent (morpho)syntax as well, the Comparative Method greatly expands our ability to examine language changes over considerable time depths. If our knowledge of language change were confined to actually attested past changes and the very recent studies of ongoing change, our understanding of processes and probabilities of change would be based on evidence from a tiny handful of languages in a tiny handful of language families - primarily, at present, languages that have been documented for several hundred years or more. And our understanding would be extremely impoverished in comparison with what we actually do know, thanks primarily to the Comparative Method.

Most significantly, then, the Comparative Method provides us with a window on prehistory. Historical linguistics is not unique among the historical sciences in being able to recover specific information that is not directly attested, from a period before any direct attestations are available; but it is certainly one of the most successful historical sciences in this regard. Certain other historical sciences, for instance paleoanthropology, have borrowed and adapted our Comparative Method in efforts to achieve comparable results. It is true, of course, that the time depths reached by the Comparative Method - perhaps 10,000 years, possibly a bit more - are very shallow compared to the relevant time depths for historical sciences such as evolutionary biology. Still, we are envied by many other historical scientists for our ability to trace linguistic features back into prehistory. The body of information about language families and their proto-languages, including the paths and results of a huge number of phonological and morphological changes, enables us to make fairly confident statements about common vs. uncommon changes, if not about possible vs. impossible changes.

A threat to the Comparative Method would not, as some language-contact specialists and longrange comparison fans have suggested, be a purely technical matter of interest only to hide-bound traditionalists. Instead, it would be a threat to the entire body of knowledge about language change that has been accumulated painstakingly by generations of scholars. Abandoning the Comparative Method would mean calling all those results into question. But from a historical linguist's 
viewpoint, the Comparative Method is too powerful to be shaken by a discovery of intractable data. The reason for this confidence in the method is that it incorporates tests, and the vast majority of the changes that have been investigated pass those tests. The method includes ways of checking its results and also ways of telling when it isn't working.

The cornerstone of the Comparative Method is the famous regularity hypothesis of sound change. Here is a typical formulation of the hypothesis (from Warren Cowgill, p.c. 1963):

If $x$ in one morpheme of language A turns into $\mathrm{y}$ in environment $z$ in $\mathrm{A}^{\prime}$, a changed later form of A, then $x$ will turn into $y$ in environment $z$ in every morpheme in $\mathrm{A}^{\prime}$, unless the process is disturbed.

What kinds of disturbances? Unfortunately, there are quite a few. Dialect borrowing can produce irregular-looking results, in doublets like English person vs. parson and university vs. varsity. In this case there were no irregular sound changes, but rather a regular change in one dialect, forms which words were subsequently borrowed into the other dialect. Analogic change can also lead to apparent exceptions to the regularity hypothesis. So, for instance, Old Russian had a consonant alternation in certain inflectional categories that originated in Proto-Slavic in the palatalization of velar consonants before a front vowel. In $a$-stem noun declension, for instance, most forms of the word for 'hand' had a stem-final $k$, as in nominative singular rõka; but the dative singular was rõtsĕ, with a [ts] affricate resulting from palatalization. Later, the Old Russian $a$-stem declension was analogically leveled in favor of the velar, so that the Modern Russian dative singular (with an unrelated vowel change) is ruke; but since [ts] affricates that were not stem-final in noun declension remain in Modern Russian, innovative froms like ruke are irregularities from the viewpoint of historical Russian phonology. Then there are the several categories of 'minor sound changes' changes that are so called precisely because they are usually or always sporadic, not regular. Metathesis (as in the alternation between ask and aks, which dates from Old English times) and dissimilation (as in English pilgrim, a borrowing from Latin peregri:nus) can also be found in some languages as regular sound changes; but haplology (as in probly from probably), for instance, is only very rarely a regular process of sound change.

A different type of disturbance is the common pattern in which a sound change is regular at its center of innovation but irregular at the periphery of its geographical spread. The most famous example is the Rhenish fan in Germany, at the periphery of the spread of a set of changes known collectively as the High German Consonant Shift. The center of innovation was in the south of German-speaking territory, and the changes spread northward via dialect borrowing. Along the Rhine River, about half-way in its northward course through Germany, there is a complex set of isoglosses that were laid down as various parts of the Consonant Shift stopped spreading, until the northernmost isogloss distinguishes a region to the north in which none of the changes occurred from a region to the south in which the only trace of the changes is that some - but not all - of the words with original $k$ underwent the change from $k$ to $(k) x$.

With all these exceptions to the regularity hypothesis, one might suppose that the hypothesis states merely that sound change is regular except when it isn't. If this were the entire story, there wouldn't be much point in hanging onto the hypothesis at all. But in fact, intensive study of sound changes over the past century and a quarter has shown that in the great majority of languages where the Comparative Method has been applied it works fine, including the assumption of regularity in sound change. There are always some irregularities, of course, but the method identifies them and sets them aside as unanalyzable residue. The irregularities therefore seldom interfere with the application of the Comparative Method because they don't occur in large enough numbers to make the regular lines of descent untraceable. As we will see below, there are exceptions to this general rule; but they are easily recognizable as exceptions, and they are uncommon. Thanks to the evaluation procedures that form a vital part of the Comparative Method, then, the method is a 
powerful tool for the elucidation of language history and even prehistory - one that no historical linguist is likely to want to abandon.

\section{The effects of deliberate changes are not always trivial}

If asked what kinds of linguistic changes speakers are most likely to make deliberately, most linguists would think first of lexical innovations. Every generation of teenagers has its own slang vocabulary and every specialized field has its own technical lexicon, to take the most obvious examples. So, for instance, a few generations ago the word crazy took on a slang meaning 'terrific, wonderful' - a lexical semantic innovation, added to its earlier meaning 'insane' - and around 1960, college students in California replaced crazy in its slang meaning with napa, derived from the location of a state mental institution. Still later, another generation replaced crazy (and, in California, napa) with cool.

Other lexical innovations are words invented entirely (e.g. names of new products such as Kleenex and Xerox); or by combining pre-existing morphemes to form new words, e.g. photocopy, which has now largely replaced lower-case xerox as a generic term; or by borrowing from another language or dialect, e.g. English algebra (from Arabic via Italian). Of course there are also more complicated coinages; email, for instance, combines the first letter of electronic with the noun mail, and snoo 'insane' was derived as a slang term by inmates at the State Correctional Institution at Pittsburgh (Pennsylvania) from the acronym of the Special Needs Unit, where mentally disturbed inmates are confined within the prison.

The reason lexical changes like these are generally considered trivial is that they don't affect a language's structure. But even linguists who recognize that structural changes can be made deliberately often seem to assume that such changes can have only minor structural effects, at least in structural subsystems below the pragmatic level. Romaine, for instance, argues that while speakers can relatively easily change their pragmatics, they can't easily introduce deliberate changes into their phonetics (1996: 111).

Probably the best-known proposal about deliberate speakers' changes is William Labov's (1994: 78):

Any general consideration of linguistic change must first distinguish between change from above and change from below...."Above" and "below" refer here simultaneously to levels of social awareness and positions in the socioeconomic hierarchy. Changes from above are introduced by the dominant social class, often with full public awareness .... Changes from below are systematic changes that appear first in the vernacular, and represent the operation of internal, linguistic factors. At the outset, and through most of their development, they are completely below the level of social awareness ....

Labov does not say that changes from above must be relatively minor, but the example he gives - the borrowing of a constricted postvocalic $r$ into an English dialect that had lacked postvocalic $/ \mathrm{r} /$ - suggests a belief that only superficial changes are likely to be made consciously and deliberately. $\mathrm{He}$ observes that borrowed features may be inconsistent with the receiving dialect's (or language's) system, so that integrating them might require significant changes in that system; but the initial change (the innovation), on his account, appears to be non-dramatic structurally. This interpretation of his view is supported by his more general statement, later in his book, about the possibilities for extensive deliberate change (1994: 598):

There is a part of language behavior that is subject to conscious control, to deliberate choice, to purposeful and reflective behavior. But as far as I can see, it is not a major part of the language faculty, and it has relatively little influence on the long-range development of language structure. 
Labov's views are (as far as I can tell) typical of those held by historical linguists more generally: deliberate change is not something that is at all likely to have more than minor influence on a system. I believe that this comfortable assumption is invalid. The circumstances under which speakers make deliberate changes in their language are not confined to a need or desire for new words and a need or desire to sound more like people of a higher social class. There is a much broader range of circumstances, and a much deeper range of deliberate structural changes, than has generally been recognized.

My own position on the possibilities in this domain is quite radical: I have argued elsewhere (Thomason 1997) that the question of linguistic possibility of a change - in this case a deliberate change - is settled as soon as a single speaker produces a single instance of the change at a single time. Whether a deliberate change will become a permanent part of that one speaker's idiolect or of the speech community as a whole is then a matter of social and linguistic probability, not possibility. Some of the examples below, therefore, will be potential language changes, not actual ones. From my viewpoint, they are linguistically equivalent to actual changes: they show that speakers have the ability to manipulate their language(s) in those particular ways.

This position leads me to reject the strong claim about the possibilities of deliberate change that was made recently by Andersen: "Surely no individual has the power to change a language, deliberately or otherwise, nor are languages known to change as the result of the speakers' collective deliberate decision" (2005: 172). Here Andersen follows a long tradition in historical linguistics, echoing views expressed across many decades and deep theoretical divides. Among these expressions are Max Müller's claim that it is 'not in the power of Man to produce or prevent changes in language' (1861); Edward Sapir's assertion that 'A speaker engaged in a change is not an agent but a victim' (1921); Noam Chomsky \& Morris Halle's assumption of 'the adult's inability to modify his grammar except by the addition or elimination of a few rules' (1968); and Roger Lass's statement that 'the mistake [in functionalist strategies for explaining language change] is considering language change to be something that speakers "do"...rather than something that happens to their languages...' (1997).

Anderson's statement (consistent with this tradition) would appear to be a claim that deliberate changes are impossible, but actually it is not entirely clear that that's what he has in mind, because he adds that " $[w]$ hat CAN happen is that some speakers make deliberate innovations, and that others adopt these because they find them useful..." (p. 172; emphasis in the original). Every change in a community's language of course involves two steps - first an innovation in the speech of one or more speakers, then spread of the innovation to the rest of the community's speakers. For some linguists, for instance most generativists, linguistic change is the innovation itself (which is assumed to occur during the process of first-language acquisition - see e.g. Lightfoot 1979, 2002); for others, for instance Lesley Milroy and James Milroy (p.c. 2003), linguistic change is not the innovation at all, but rather the spread of the innovation through the speech community. I would argue that this is a false dichotomy, because a full analysis of any change must surely include both the innovation and its spread. If this is correct, then Andersen is at best half right in his claim. But in any case there are counterexamples to his claim about no-speakers'-collective-decision (see below, $\S 3.1$ and $\$ 3.3)$.

In the rest of this section I will give examples of three types in support of the claim that speakers' deliberate choices can affect a language's structure significantly. First, I'll discuss examples of phonological CORRESPONDENCE RULES that bilingual speakers often use in adapting loanwords to their own language's structure $(\S 3.1){ }^{2}$ These rules serve to highlight the extent to

\footnotetext{
${ }^{2}$ All the comments I make in this paper about bilingual speakers and situations also apply to multilingual speakers and situations. To avoid stylistic clumsiness, I'll usually use the term 'bilingual' as a cover term for both, whenever both apply.
} 
which speakers can and do make deliberate changes. Second, and somewhat paradoxically, I'll discuss deliberate NON-changes - resistance to lexical interference, in particular (§3.2). Here too my goal is to show that speakers can, to a surprising extent, control what does or doesn't happen to their language. And finally, I'll discuss examples of deliberate structural changes (§3.3).

Before beginning this survey, I should add two preliminary comments. First, all the examples of correspondence rules and deliberate non-change are from language contact situations. This does not mean that there are no examples, at least of deliberate non-change, in (relatively) monolingual contexts, but I haven't found any yet. (Possibly the famous archaizing of Icelandic as part of the process of standardization fits here, for instance, though one might prefer to argue that two different languages were involved, Modern Icelandic and Old Norse.) Only in the third category, deliberate structural change, are there clear examples of changes within a single language. Second, I must emphasize that it cannot be proved that every example below was actually deliberate. But all are cases in which speakers can be shown to have the conscious knowledge required to effect the change, and some are cases - most of them potential rather than completed changes - in which speakers have certainly decided to make particular changes.

\subsection{Correspondence rules}

Correspondence rules, or (in Jeffrey Heath's 1989 terminology) borrowing routines, are well known from a wide variety of situations in which related languages are in contact. They provide excellent evidence of bilingual speakers' ability to manipulate equivalent forms, usually phonological, in their two languages. A typical example is reported from Fayyoum Oasis Arabic by Rudolf de Jong (p.c. 1995). Fayyoum Oasis is about $100 \mathrm{~km}$. from Cairo, and since Fayyoumis sell their agricultural products in Cairo markets and/or work in the construction industry in Cairo, they have extensive contacts with Cairene Arabic. Two phonological correspondence sets, due to an earlier monophthongization in Cairene, are Cairene $o:$, $e$ : vs. Fayyoum Oasis diphthongs $a w$, $a y$, as in Cairene be:t : Fayyoum Oasis bayt 'house' and Cairene mo:t : Fayyoum Oasis mawt 'death'. When European loanwords enter Fayyoum Oasis Arabic via Cairene Arabic, the borrowers adapt the words in a way that shows that they've applied correspondence rules to diphthongize the Cairene (and the original European) monophthongs: so Cairene tilifo:n 'telephone' turns up in Fayyoum Oasis as talafawn, and Cairene gine: ' 'guinea' is ginayh in Fayyoum Oasis.

A less typical example, because it involves two competing correspondences, is illustrated in Thompson River Salish loanwords taken from another Salishan language, Chilliwack. Thompson cognates with Chilliwack have two different correspondences involving $l$, namely, Thompson $l$ : Chilliwack $l$ and Thompson $n$ : Chilliwack $l$. Speakers display their knowledge of these correspondence sets in their handling of loanwords. So, for instance, the loanword $k^{w} u k^{w} n s$ 'high cranberry' has an $n$ in Thompson in spite of the fact that the Chilliwack source word has an $l$. In analyzing this example, Kinkade observes, "Recognizing that Chilliwack 1 was often derived from $\mathrm{n}$, the Thompson form changed this consonant "back" to n, although the Squamish cognate shows that it is actually derived from 1" (1995: 35; Squamish is another Salishan language, more closely related to Chilliwack than to Thompson).

The question arises, of course, as to whether the application of this correspondence rule is conscious or subconscious. Certainly it needn't be the case that application of correspondence rules is always accessible to the borrower's conscious mind, and some authors appear to take the position that subconscious knowledge is the norm. This may be true, for instance, of Ross \& Durie, who say that speakers who "regularly use two or more lects...have an intuitive grasp of...sound correspondences" and use them "to convert the phonological shapes of words from one lect to another" (1996: 29). 
But there is direct evidence that speakers often - maybe typically - know exactly what they are doing, at least retrospectively but also beforehand, when they apply correspondence rules. Martha Ratliff has observed that 'speakers of languages like Arabic and Tamil, who have knowledge of a literary standard that is quite different from the colloquial language..., can retard the process of natural language change in the colloquial quite consciously so that the two do not drift apart past a tolerable limit' (p.c. 2000). An example is a change introduced by Tamil speakers into their colloquial speech: they deliberately reversed an umlaut rule, modeling the change on literary Tamil, when the umlauted vowels became socially stigmatized (Pargman 1998).

A somewhat similar reversal, but with a quite different motivation, is found in an example from the Hakha dialect of Lai Chin, a Tibeto-Burman language of the Kuki-Chin-Naga branch (this example comes from F. K. Lehman, p.c. 1999). Lai is very closely related to Laizo (of Falam); both are spoken in the Chin State of Burma (Myanmar). Lai, but not Laizo, had undergone a sound change that turned vowel + liquid sequences in syllable codas into diphthongs - that is, deleting the liquid consonant and diphthongizing the preceding vowel. But by 1957, when Lehman began his fieldwork in Hakha Lai territory, Standard Lai had apparently reversed that sound change: it regularly had simple vowels followed by coda liquids. He later learned why and how this reversal had happened. In the last decade of the $19^{\text {th }}$ century, the Hakha chiefs became indignant because the British authorities had made Falam their headquarters in the region and had adopted Laizo as their official administrative language there. The British action conferred prestige on Laizo. In an effort to regain what they viewed as their proper regional status, the Hakha chiefs decreed that Hakha be pronounced just like Laizo - including the coda monophthongal vowel + liquid sequences, which Laizo retained. (In 1962 Lehman was introduced to some very elderly Lai speakers who still had the coda diphthongs without coda liquids; these were people who had not followed the chiefs' decree. But everyone else had the coda monophthongs and liquids.) Lehman explains that the Lai change was possible because the correspondences were 'acutely transparent', and moreover multilingualism was pervasive in the region, so that Lai speakers could easily apply what amounts to a correspondence rule in reverse and replace their native codas with the Laizo phonotactic pattern. ${ }^{3}$ This example is one of the clearest I've found that shows (pace Andersen 2005) that groups of speakers can indeed introduce new linguistic structure by deliberate decision.

Here is a final example, a particularly striking instance of conscious manipulation of correspondence rules, from Alan Dench's fieldwork (p.c. 1993 and 2001: 117-118). Some years ago, Dench was eliciting a wordlist while conducting salvage linguistic research with the one of the last two speakers of Martuthunira, a western Australian language. This speaker gave him the word ngal.yu for 'wild onion'. But later he checked the list with the other remaining speaker, who told him that the word for 'wild onion' was partunya, not ngal.yu. Dench went back to the first speaker and told him what the second speaker had said; ah yes, said the first speaker, that's right, it is partunya. But then why did you tell me it was ngal.yu?, Dench asked. Well, said the first speaker, Panyjima speakers say ngarlku, and Yindjibarndi has ngarku, and Kurrama has ngartku; so it OUGHT to be ngal.yu in Martuthunira! The sound correspondences among these closely-related languages are quite regular, and the speaker was perfectly aware of the regularities. Was Dench's consultant applying his correspondence rules to invent a loanword? Maybe, maybe not; if Martuthunira weren't moribund, and if his coinage of ngal.yu stuck in his own idiolect and then spread to other speakers (who would also have been multilingual), then the native word for "wild

\footnotetext{
${ }^{3}$ Note that this example is irrelevant to the recurring theoretical question of whether sound changes can be reversed: the theoretical issue concerns internally-motivated change (and most historical linguists believe that it is impossible to reverse a completed sound change through strictly internally-motivated change). The reason is that this is a case of borrowing, in effect: in applying the correspondence rule, Lai speakers were adopting the Laizo vowel + liquid pattern that corresponded to their own diphthong-but-no-liquid codas.
} 
onion' would have been replaced by the multiple-source loanword. The point is that the first step in the process was taken as soon as he came up with ngal.yu.

Can the use of correspondence rules be so extensive as to interfere with attempts to apply the Comparative Method, especially for subgrouping related languages? The answer to this question is definitely yes. In a number of cases from different parts of the world, closely-related languages have exchanged so many loanwords, with (and probably also without) the application of correspondence rules, that the subgrouping of the languages is impossible to determine. The fact of genetic relationship is not in doubt, but the varying degrees of relationship within the family or subfamily and the actual changes undergone by individual daughter languages cannot be established. This problem was noted at least as early as 1965, by Wayne Suttles. After noting that "the possibility of pervasive intrafamilial borrowing [among Halkomelem-Straits Salishan languages] is great enough to cast doubt on the whole procedure of subgrouping by percentages of shared vocabulary,, ${ }^{4}$ Suttles suggests that borrowings might not be recognizable as borrowings in part because 'the borrowers were quite aware of the correspondence [between certain vowels]... and simply reshaped the word accordingly" (1965: 21-22, 25).

Ross \& Durie also emphasize the subgrouping problems raised by multiple phonological correspondences in closely-related languages. They report George Grace's finding, from his research on Melanesian languages of New Caledonia (Grace 1996, and also e.g. Grace 1981, 1990), that multiple phonological correspondences yield a "system" with "just a few examples of each correspondence', and his conclusion that 'it is impossible to separate "regular" (inherited) from "irregular" (borrowed) words (Ross \& Durie 1996: 28-29). This is the context for their own remark, quoted above, about speakers applying correspondence rules.

\subsection{Deliberate non-changes}

Resistance to change, or refusal to change, often manifests itself in the non-borrowing of words. It is easy to find examples in the literature, from cultures all over the world. It is much less clear to what extent speech communities can resist structural interference, given the lesser salience of structural, as opposed to lexical, features. Among the Tewa people of Arizona, for instance, language mixing and borrowing are heavily frowned upon (Kroskrity 1993). All Arizona Tewas are bilingual in Hopi, whose speakers have surrounded the Tewas for three hundred years; but Tewa is used especially in religious ceremonies, where any use of Hopi is considered inappropriate. Tewa has therefore undergone very little lexical interference from Hopi. Arizona Tewa has also borrowed very little from Spanish, which many Tewas also speak. There has, however, been some structural borrowing into Arizona Tewa from Hopi, including a passive suffix (Kroskrity 1993: 64, 74-75).

By contrast, Montana Salish speakers in Montana have borrowed neither lexicon nor structure from English, in spite of a hundred and fifty years of increasingly intense pressure from the dominant Anglo culture and language. The absence of loanwords is not complete; but the handful of English loanwords, mostly place names, hardly matches the degree of modern Salish speakers' acculturation to mainstream U.S. culture, which is very extensive, even extreme. The names for new things are constructed by Salish speakers out of native morphemes, and usually with native concepts. So, for instance, the Salish word for 'automobile' is p'ip'úyšn, literally 'it has wrinkled feet' - named after the appearance of tire tracks - and the word for 'drive a car' literally means 'make a domestic animal go straight'.

\footnotetext{
${ }^{4}$ Suttles is talking here about lexicostatistic techniques, but similar difficulties will arise with currently standard methods of subgrouping.

${ }^{5}$ This lack of borrowing appears to be an areal Northwest feature. Nez Percé, a Sahaptian language whose speakers have had close ties to the Montana Salish people for many generations, shares the lack of borrowing and the coining of native words for borrowed cultural items, and the same phenomenon has
} 
In any case, resistance to lexical borrowing has been more widely noted than resistance to structural interference. Here are a few more examples. Walapai (Hualapai), a Yuman language spoken in Arizona, has undergone 'negligible' interference from English, '[i]n spite of prolonged and intensive contact between speakers of Walapai and speakers of English'; this is 'a strictly monolingual response in an increasingly bilingual situation' (Winter 1992: 222). Tariana, a North Arawakan language of the Vaupes River region in Brazil, has borrowed very few words from either neighboring East Tucanoan languages or Portuguese in spite of very close contacts and extensive multilingualism (Aikhenvald 1996: 85); the apparent reason, Aikhenvald argues, has to do with the importance in the region of language as a 'badge of ethnic identity', and the consequent disapproval of language "mixing", specifically lexical mixing. According to Norman (1988: 20), current Modern Chinese "is very resistant to borrowing foreign terms outright', instead creating new words out of native parts; by contrast, early 20th-century Chinese borrowed many words for new Western 'technology and political and economic concepts" from Japanese. A final example is the East Ijo language Ibani of Nigeria's Niger Delta region, as described by Kay Williamson (p.c. 1996, in part citing work by Robin Horton). In the main Ibani town, Bonny, Ibani speakers are all bilingual in Igbo, but they are much concerned to maintain the purity of Ibani. When eliciting Ibani wordlists, outside scholars find that Ibani speakers carefully avoid Igbo loanwords. They do in fact have some Igbo loanwords in their language, but they know which words are borrowed and avoid them deliberately in a formal elicitation setting - a potential resistance to interference, if not an actual one.

A question arises in connection with these examples: are there perhaps structural deterrents to lexical borrowing in some or all of these cases? Maybe, as has sometimes been suggested, morphological complexity makes it difficult or impossible to insert a borrowed lexical item into a potential receiving language's word structure? If there are such barriers, then the reason for the lack of loanwords in (for instance) Montana Salish could be that, rather than speakers' choices. But the answer to the question is no: there is solid evidence to show that even the most elaborate morphological structures can accommodate borrowings. A fairly trivial example is the Montana Salish neologism mumuwlš 'the sound of mooing', which was invented as a joke by a Salish elder in 1998; it isn't a permanent loanword, but it could in principle become one, and it has both an appropriate Salish suffix -wlš and the Salish prefixed reduplication ( $m u$ - in this case) that regularly accompanies this suffix. More elaborate examples, morphologically speaking, have been reported for the most polysynthetic languages of the Americas, including Athabaskan, Algonquian, and even members of the polysynthetic and incorporating Eskimo-Aleut language family.

In addition, we often find contrasts between languages without much borrowing and closelyrelated languages with lots of borrowing. Although Arizona Tewa has borrowed very little from Spanish, for instance, and has no phonological interference at all from Spanish, the variety of Tewa spoken near the Rio Grande has considerable interference from Spanish (Kroskrity 1993). And while Ibani speakers have borrowed little from Igbo and are quite aware of Igbo loanwords, speakers of the closely-related Eastern Ijo language Kalabari use Igbo loanwords unselfconsciously, although they are reluctant to confess to knowing any Igbo at all (Kay Williamson, p.c. 1996). It seems clear, then, that it is the speakers' attitudes that dictate the borrowing or non-borrowing of material from another language, not the linguistic structures themselves.

been reported for Salishan languages spoken elsewhere, as well as for other Northwest languages. Nez Percé has, however, borrowed a sizable number of words from Salishan languages (Pharris \& Thomason 2005). 


\subsection{Deliberate structural changes}

Deliberate changes can be found in all grammatical subsystems, from the phonology to the morphology to the syntax and the lexicon, including lexical semantics as well as the forms of words. Examples are easiest to find, however, for phonological and lexical changes, and it is likely that these are the most frequent. Motivations for making deliberate changes, as we have already seen, vary considerably from culture to culture. In this section I will try to illustrate the widest possible range of both linguistic features and social motivations.

One general type of motivation corresponds to what Trudgill has called HYPERDIALECTISM - a change made to increase the difference between one's own speech and someone else's. In England, for instance, Trudgill found examples of added postvocalic $r$ 's along the borderlands between rhotic (" $r$-ful") and non-rhotic (" $r$-less") English dialects. On the rhotic side of the border, rhotic speakers inserted an $r$ after vowels that appear elsewhere in rhotic $\mathrm{V} r$ vs. non-rhotic $\mathrm{V}$ correspondences namely, in words like walk, calf, straw, and the first syllable of daughter (1986: 75). The result is the pronunciation of postvocalic $r$ in a sizable number of words that had no $r$ etymologically. Trudgill comments (1986: 76) that

We can regard hyperdialectal /r/ on the rhotic side of the rhotic/non-rhotic border areas as a way of reacting to and resisting new, non-rhotic pronunciations, since it is obvious that throughout England rhotic pronunciations are receding quite rapidly in the face of non-rhotic.

A variant of this motivation can be seen in an example from Ma'a, a mixed language spoken in northeastern Tanzania. Over the past two or three centuries Ma'a has undergone such extensive Bantuization that the remaining vestiges of its original Cushitic (or at least non-Bantu) structure have virtually disappeared, though much non-Bantu lexicon remains. One of the few remaining non-Bantu structural features is a voiceless lateral fricative, typical of Cushitic languages but not of the Bantu languages of the region. This phoneme, which has always been present in the Cushitic vocabulary of Ma'a, is viewed as particularly difficult and exotic by the Bantu speakers among whom the Ma'a people live. So Ma'a speakers emphasize the differentness of their other language (they are all bilingual, speaking at least one Bantu language fluently in addition to Ma'a) by introducing the lateral fricative into Bantu words too, thus making their speech less Bantu-like (Mous 1994: 199). Dench speculates in a similar way about the maintenance of the phonological correspondence rules discussed above: "It is at least conceivable that these differences [in phonotactic patterns] are consciously maintained in order to preserve some distinction between the different lects" (2001:118).

The urge to make one's own speech more different from the neighbors' speech is not confined to phonology. Wright describes the following case (1998), citing Yakov Malkiel. Malkiel, Wright says,

pointed to several cases in which sixteenth-century Portuguese had two variants available (in morphology or phonetics, but it also applies to vocabulary), both indigenous, and they perhaps consciously - chose the one that was least like Spanish, asserting their identity that way.

Wright observes that this is still happening today in non-Castilian regions of Spain, especially in vocabulary: where Catalan or Galician 'has two words that are for practical purposes synonymous, one of which is like the Castilian word for the same meaning and the other of which is not, the dictionaries and the standardizers...have tended to prefer the one that isn't like Castilian'.

The difference-enhancing alterations discussed so far don't introduce major changes into the linguistic system, but sometimes the urge to be different results in more dramatic distortion distortion that potentially, at least, could interfere with the application of the Comparative Method. The creation of entirely new languages belongs in this general category, but it's so much more 
extreme that we'll consider it separately at the end of this section. In the present context, a morphological change described by Laycock (1982) and cited by Kulick (1992: 1-2) is especially impressive. Uisai, a language spoken on Bougainville Island in Papua New Guinea, has 1500 speakers; it is a dialect of Buin, which otherwise has 17,000 speakers distributed among several dialects. Concerned about the close similarity of their language to the other Buin dialects spoken by their neighbors, Uisai speakers switched all their masculine and feminine anaphoric agreement markers so that masculine elements systematically correspond to feminine elements in neighboring dialects, and vice versa. Kulick comments that

New Guinean communities have purposely fostered linguistic diversity because they have seen language as a highly salient marker of group identity....[they] have traditionally seized upon the boundary marking dimension of language, and...have cultivated linguistic differences as a way of 'exaggerating' themselves in relation to their neighbors....' (1992: 1-2).

Similar comments on the New Guinea situation can be found in Foley (1986: 9, 27, et passim). Kulick also mentions a meeting in which villagers in one community decided to replace certain words with other words in order to 'be different' from speakers of other dialects of the same language (ibid. p. 2).

On the other side of the world, the same urge to be different seems to have played a decisive role in a dialect of Lambayeque Quechua, where speakers systematically distorted their words in order to make their speech less like their neighbors' speech (David Weber, p.c. 1999, citing research by Dwight Shaver). A major (or perhaps the major) process of lexical distortion in this case was metathesis, as in yaw.ra from yawar, yurqa from yuraq, -tqa from -taq, -psi from pis, and kablata from kabalta.

The crucial point here is that such changes - especially, probably, lexical distortion and lexical replacement - could easily disrupt the application of the Comparative Method completely, if they were thoroughgoing enough. In fact, as we will see below, sometimes these processes have produced effects this extreme.

Another common motivation for introducing deliberate changes on a large scale is to keep outsiders at a distance - a linguistic distance - either by making a language unintelligible to outsiders who are fluent bilinguals or by preventing outsiders from learning the language in the first place. This phenomenon is familiar to anyone who ever learned a "secret language" like Pig Latin or invented one as a child (and the percentage of secret-language-inventers is probably higher among linguists than in the general population). Pig Latin involves systematic universal metathesis at the word level; other invented children's languages, like the one my friend Molly Mason and I made up around 1952, have inserted elements. We called our private language Harpy Garpy Larpanguarpage, and it had just one rule that distinguished it from English: 'Insert -arp- before the vowel of every syllable'. Here is a typical sentence in it, using standard orthography:

"Tharpis sarpentarpence arpis wrarpittarpen arpin marpy sarpecrarpet larpanguarpage, arpand arpif arpI warpere sarpayarping arpit arpalarpoud yarpou prarpobarpablarpy warpouldarpn't barpe arpabarple tarpo arpundarperstarpand arpit arpeasarpilarpy arpunlarpess yarpou arpare arpa varperarpy tarpalarpentarped arpinstarpant darpecarpodarper."

Made-up languages like Pig Latin and Harpy Garpy Larpanguarpage, with their very simple rules, are crude but effective: unless you know the rule, you can't understand what's being said. But cracking the code is easy, given a reasonable amount of data, so it probably isn't surprising that no entire speech community (as far as I've been able to discover) makes use of such a language for ordinary communicative purposes. Another reason might be that speech communities with hundreds of members are more complex social entities than small groups of schoolchildren, and that the simplicity of children's secret languages can't be maintained in a larger group. Whatever the reason 
is, the community-wide secret languages that do exist (and several are known from the literature) have much less regular and less straightforward structures than children's play languages.

Sometimes, though very rarely, a secret language can become stabilized and embedded in daily life to the extent that it becomes a speech community's main language. An example is Mōkkī, a language that was spoken in Baluchistan, in what was then British India and is now Pakistan, early in the $20^{\text {th }}$ century (and, for all I know, it may be spoken there still). It was reported by Bray in the Baluchistan volume of the 1911 Census of India; because his account shows the complexity of the lexical distortions so clearly (1913: 139-140), I'll quote it at some length:

There is a certain appropriateness in winding up a survey of the languages of this province with... Mōkkī, the cant of the Lōrịs, for it's a hotchpotch of the lot. ...It is an artificial jargon, which the Lōrīs have mechanically invented on the basis of the language of the people among whom they live, and which they more especially employ when they want to keep their meaning to themselves...And yet so universally and successfully is the jargon used, that it seems doubtful whether its artificiality suffices to debar it from being classed as a language. However artificial its origin and character, it is at any rate acquired naturally and as a matter of course by Lōrīs children; it is no longer, it would seem, simply a secret patter; it is becoming a language for the home-circle. ...It is all very simple. Take any word from any language, and turn it inside out:...chukak 'dog' [from] Brahui kuchak; randum 'man' [from] Persian mardum. But though this is their chief device for obscuring the meaning of everyday words, there are several others. ...Sometimes they add a suffix. ...Prefixes are affected still more. ...or they resort to soundchanges...the thin disguise of isolated words and the rapidity of connected sentences, blurred in the rapidity of speech, [make] both Brahui and Baloch admit freely that Mōkkī is beyond them.

I don't know of any other stable community languages that had their origin in massive lexical distortion, but other cases have been reported of the same general type - though (apparently) without a stable enough existence to include either first-language acquisition or everyday usage throughout the community. One is Lunfardo, which Jose Hualde (p.c. 1992) describes as a 'jargon that was developed in Buenos Aires at the beginning of [the 20th] century among certain social groups'. Some Lunfardo words come from Italian dialects without distortion, but many others were derived from Spanish words via metathesis, e.g. feca con chele from cafe con leche and gomia from amigo. Hualde reports that the language was widespread enough to inspire the publication of Lunfardo dictionaries, and that many Lunfardo words made their way into common usage in Argentina.

It's not hard to find similar reports of secret languages elsewhere in the world. To give just one further example, during the $17^{\text {th }}$ century a visiting European once attended a meeting at which the Delaware Indians planned to substitute different words for their native lexicon when they went to war against the Iroquois, so that their enemies wouldn't understand them (Lindeström 1925: 203204).

Less drastic but still significant distortions have been made by people who wish to prevent outsiders from learning their language. In a sizable number of contact situations around the world, there is direct evidence that people have deliberately withheld their language from others, either by refusing to speak it to outsiders at all or by distorting it. The second method of withholding is the one of interest here. It has been reported from a variety of situations in which pidgin languages have emerged, languages that are based in part on the foreigner-talk of the lexifier-language speakers. The 17th-century Delaware-based pidgin, for instance, was thought by many Europeans to be the regular language of the Delaware Indians, but at least one Dutch missionary, Michaëlius, noticed the difference and said that the Indians deliberately distorted their speech in conversing with Europeans (Jameson 1909: 128):

[They] rather design to conceal their language from us than to properly communicate it, except in things which happen in daily trade; saying that it is sufficient for us to understand them in 
that; and then they speak only half sentences, shortened words...; and all things which have only a rude resemblance to each other, they frequently call by the same name.

Similar distortions and simplifications are reported from other places too, among them Ethiopia, where two foreign fieldworkers spent seven months learning what they thought was Hamer but which turned out to be a kind of Pidgin Hamer instead (Lydall 1976: 397), and New Guinea, where a late-19th-century missionary tried to learn Motu but discovered, very belatedly, that Motu speakers had spoken to him only in a foreigner-talk version of their language - a version that later, together with other varieties of foreigner-talk Motu, coalesced into the pidgin Hiri Motu (Dutton 1997: 16-17).

A related motive underlies the men's version of Mayrinax, a dialect of Atayal (a Formosan language). For ritual purposes connected with the hunt, Mayrinax-speaking men distorted many of their words in ways that are reminiscent of Mōkkī - not by a simple rule, but by various phonological manipulations, among them metathesis and the replacement of certain sounds by others; they also apparently made up new words to replace ordinary ones (Stan Starosta, p.c. 1999, citing $\mathrm{Li}$ 1980, 1982). The result is a sharp lexical differentiation between men's and women's speech.

A different but still related motive seems to have been at work in a much less sweeping, but still very interesting, case of withholding - specifically, the withholding of a single phoneme in the presence of outsiders. Daniel Everett (p.c. 1995), after studying Pirahã intensively for years while visiting and then living among its speakers, had become fully fluent in the language. He was therefore astonished when he suddenly heard a new sound, new not only to him but virtually unique in the world's languages: a linguo-labial stop in which the tongue came far out of the mouth. Previously, speakers had substituted other phonemes (which occurred elsewhere as well) in words that now turned out to have this phoneme. Everett could account for its sudden appearance only on the assumption that the Pirahã speakers - for whatever reason - had deliberately withheld it from him until they finally accepted him fully into their community.

Yet another motive for introducing deliberate changes into one's language could be called the zeal of language standardizers. The story about how Standard English acquired such rules as the anti-split-infinitive rule - namely, by 18th-century grammarians' decision to follow a Latin model is familiar. But the impact of the changes introduced into Estonian by the language reformer Johannes Aavik is more impressive by far. Early in the $20^{\text {th }}$ century, Aavik invented about 200 new words to fill what he saw as lexical gaps and to replace 'linguistically inferior and awkward compound constructions' (Saagpakk 1982). About 30 of these neologisms were included in Muuk 1940, an official dictionary of Estonian, and according to Saagpakk 'many of these are now in general usage', e.g. relv 'weapon' and roim 'crime'.

But Aavik's innovations were not confined to the lexicon. He introduced morphological and syntactic features as well, and some of these have also been generally accepted in the language (Ilse Lehiste, p.c. 1999). Commenting on this phenomenon, Oksaar observed that Aavik's innovations "are proof that arbitrarily coined new derivational and inflectional morphemes and new grammemes - such as the synthetic superlative - can be wholly accepted by the language users and...incorporated into the language" (1972: 491). Aavik's innovations (which also counterexemplify Andersen's claim about speakers' inability to change their language by deliberate decision) were largely internally motivated and thus unconnected with contact-induced change; but he was apparently inspired, for some of the changes, by felicitous structures in German (including the synthetic superlative formation).

A final category of deliberate change is convergence toward another language. One example though not of a completed change or even of a change in progress - occurred in a single elicitation session with a Montana Salish elder. As noted above, Montana Salish speakers don't borrow either 
structure or words from English. But they certainly have the knowledge and ability to do so, and occasionally, often for fun, they make use of that knowledge. In a striking instance of deliberate accommodation to English, during a sentence-elicitation session, the elder translated several English sentences into Salish with sentential calques. When asked for a translation of 'Johnny stole huckleberries from Mary', for example, he gave.. Čoni naq ${ }^{w}$ ' $t$ st'ša $t l$ ' Mali (lit. 'Johnny steal PARTICLE huckleberry from Mary'). The structure of this Montana Salish sentence, most notably the uninflected intransitive verb form, makes the sentence look quite close to the English word order and superficial structure. Such sentences are fully grammatical in Montana Salish, but they are very odd except in certain stylistically marked discourse contexts. A more usual translation of this sentence would have a morphologically complex transitive verb form: $T$ Čoni naq ${ }^{w}$ '-m-1-t-s Mali ci $t s t$ 'ša (lit. 'PARTICLE Johnny steal-derived.transitive-relational-transitive-he Mary that PARTICLE huckleberry'). When I finally asked if these English-like sentences weren't rather, um, Englishy, he agreed that they were, but said that he thought that's what I wanted, since I had given him English sentences to translate. He then offered the more natural Salish versions of the ditransitive sentences, showing a ready ability to go back and forth.

Although this example is startling in its degree of alteration of ordinary (contextually unmarked) Salish structure, it is not unique - probably very far from unique, though I have not seen many comparable examples in the literature. At least one other very similar example has been reported, however. In eliciting data from bilingual Nisgha/English speakers, Tarpent (1987) found an interesting, and quite systematic, accommodation of ergative Nisgha structure to accusative English structure, specifically in the use of object pronouns. The ordinary Nisgha usage is reflected indirectly in some Nisgha speakers' English, in the deletion of an object under identity with the object of a previous clause, as in They heard him, but couldn't see (Tarpent 1987: 157). Overt object pronouns are stylistically marked in such constructions in ordinary Nisgha and are used only for emphasis, but they are inserted freely into Nisgha clauses when 'the Nisgha speaker strives to approximate the English utterance' during an elicitation session (p. 158). In fact, Tarpent observes, "some bilingual speakers asked to translate an English text into Nisgha tend to stick very close to English surface structure, resulting in strange sentences if not misunderstanding" (p. 157).

These two examples show that bilingual speakers are able to manipulate one language's resources quite consciously to approximate the structure of another language. Interference could certainly occur if speakers were to start exploiting this mechanism systematically; Montana Salish morphology and syntax would change drastically if all the remaining speakers began producing such English-like sentence structures outside the restricted discourse contexts where they are appropriate, and Nisgha syntax would change significantly if the speakers inserted object pronouns in conversation as well as during elicitation sessions. But, as already noted, they choose not to do so.

Some readers may doubt that the motives and linguistic processes discussed so far in this section would ever lead to results that could cause serious problems for the application of the Comparative Method. Although some of them seem rather convincing - especially the more extreme instances of lexical replacement and distortion - none is as conclusive as the handful of well-documented BILINGUAL MIXED LANGUAGES that emerged abruptly as part of a process of creating a new ethnic group. I will describe just two of the best-known cases very briefly here, Michif and Mednyj Aleut.

Michif, a combination of Cree (an Algonquian language) and French, is spoken primarily in North Dakota, Manitoba, and Saskatchewan. It arose as one of the languages of the mixed-blood French/Indian population known as the Métis, and has existed at least from the early decades of the $19^{\text {th }}$ century (Bakker \& Papen 1997: 301) - namely, from the period at which the Métis first emerged as a clearly identifiable political and economic population. The origin of both the people and the language lies in the mixed marriages between French Canadian trappers and traders and Algonquian-speaking wives, most or all of whom spoke Cree either natively or as a lingua franca. 
The structure of Michif is more Cree than French, and the Cree parts leak into the French parts (but not vice versa). Specifically, the verb phrase - including fully elaborated Cree morphology, which is very complex indeed - and the sentence structure are Cree, while the noun phrase is comprised of French lexicon, phonology, morphology, and syntax. There is no question about the language's independence from Cree and French; most current speakers know neither Cree nor French, though they are fluent in English and sometimes in Ojibwa as well.

Mednyj Aleut, a combination of Aleut and Russian, is named for the island on which it was spoken until fairly recently, when the few remaining speakers were moved to a neighboring island. Like Michif, it emerged in a mixed-blood speech community, in this case one that arose in the $19^{\text {th }}$ century when Russian fur seal traders came to work on Mednyj (Copper) Island and produced offspring with Aleut women. The children of these unions held an economic position that was more favorable than that of the Aleut seal hunters, but they were looked down on by both Russians (for being non-white) and Aleuts (for being illegitimate). The structure of the language is primarily Aleut, with moderate interference from Russian - except for the finite verb morphology, which was borrowed wholesale from Russian to replace the original Aleut finite verb inflection. Nonfinite verb inflection, as well as nominal inflection, is still Aleut, with all the categories and morphemes that are characteristic of Aleut elsewhere; but the finite verb inflection has all the quite different Russian categories and morphemes.

One crucial point about both Michif and Mednyj Aleut is that they are not the product of ordinary gradual language change of any kind. Even when they are compared with ordinary contactinduced change, which may proceed more quickly than (most?) internally-motivated change, the genesis of these and other bilingual mixed languages is still aberrant. In fact, it does not look like language CHANGE at all; instead, it looks like the deliberate creation of a new language by bilinguals, over a relatively short period of time (probably two or three decades at most). It isn't hard to find a motive for language creation in these cases, either: both of these mixed-blood populations were politically and economically distinct from the "pure"-blood communities, and both therefore had a motive for distinguishing themselves further by their language. And that seems to be what they did: each group exploited the linguistic repertoires of its two languages to form a new language to mark its ethnic identity. And finally, both of these cases, as well as other bilingual mixed languages, pose an obvious challenge to the Comparative Method, which is designed to establish the existence of, and to reconstruct, at most one parent language. The Comparative Method would set aside the entire noun phrase of Michif and the entire finite verb inflectional system of Mednyj Aleut as unanalyzable residue, for instance.

Before leaving the topic of bilingual mixed languages, I wish to emphasize that they are unusual only in their stability, their possession of lexicons and grammatical norms that must be learned by anyone who wants to speak them: they are not ephemeral, ad-hoc mixtures, but languages that will endure as long (and only as long) as their speech communities endure as separate speech communities. Like children's secret languages, and also like teenage slang, ephemeral and ad-hoc bilingual mixtures are probably quite common around the world. Some of the stories are anecdotal; Ad Backus (p.c. 1999) reports, for instance, that bilingual young adult Dutch speakers often insert English words into Dutch morphosyntax in conversation because talking this way is considered trendy, and that the percentage of English words in such conversations often approaches total replacement of Dutch vocabulary. And Deumert, writing about English-Afrikaans language contact in South Africa, refers to the "playful and creative character of language use in Cape Town's coloured working-class communities", with results that might reasonably be called an incipient mixed language (2005: 131). She includes (2005: 131) a striking quotation from Stone (2003: 391):

I suggest that the dialect constitutes linguistic bricolage. The "ends", the "standard" dialects from which it is composed, are appropriated and adeptly made to constitute a new "means", the working-class dialect, under the noses (so to speak) of the sanctimoniously dominant from 
whom it is taken. The processes of construction are partly serious, rule-bound and consequential, and partly creative, playful, whimsical and unpredictable, and the two processes interweave and oscillate in unstable equilibrium...

If groups of speakers can go this far, they can certainly go further to create and stabilize a fullycrystallized new language. The processes of creation are all familiar from other areas of human linguistic activity, especially in situations of language contact (see Thomason 1995 for discussion); it is only the results that differ strikingly from the results of ordinary language change.

\section{Implications for the Comparative Method}

Given the kinds of deliberate changes we've examined, an important question arises: why is it that the Comparative Method works so well, if speakers can and do decide (at least in some cases) what changes to make in their language? It seems to me that there are three different answers to this question; the first stands apart, but the second and the third conspire (as it were) to explain the overwhelming success of the Comparative Method in the great majority of cases.

4.1 ANSWER \#1. First, it is clear by now that the Comparative Method DOESN'T always work. As we saw above, subgrouping fails in such cases as Halkomelem-Straits Salish (Suttles 1965) and the languages of southern New Caledonia (Grace 1996), thanks to truly pervasive borrowing and the application of correspondence rules that further obscure the distinction between loanwords and inherited vocabulary. This result, which is by no means unique to these two cases, should perhaps not be surprising: as Lass has pointed out, there are parallels in biology, where "assignments to higher taxa like phyla, orders, and classes are often easier and less controversial than to genera or species" (1997: 143). And, although it is not relevant to the issue of deliberate change, numerous scholars have also pointed to the difficulty or impossibility of arriving at a solid subgrouping model for languages (or dialects) that arose as a dialect continuum.

Sometimes, however, the Comparative Method fails completely. It can give no solid result for abruptly created bilingual mixed languages, since they didn't arise by ordinary language change and (therefore) their structures and lexicon can't all be traced primarily back to a single parent language. Sometimes, too, gradual change can lead to a language that must be considered mixed because it preserves only part of the lexicon and perhaps a few structural features of its putative parent language. In some such cases, at least, speakers' choices are also involved - for instance in New Guinea, where, as we have seen, speakers make deliberate changes in their languages to differentiate them more sharply from their neighbors' languages. So when we read, for instance, that the Adzera language "has been so heavily influenced by the adjoining Papuan languages that it betrays its Austronesian affiliation only in some basic vocabulary and a few morphemes" (Foley 1986), we might want to question whether it can now be properly said to have any Austronesian affiliation. If Adzera has little or no Austronesian structure, then it will be impossible to find systematic correspondences between Adzera and Austronesian languages in all grammatical subsystems, and impossible to use Adzera data in reconstructing Austronesian structure, including phonology.

Another case that has been suggested as a failure of the Comparative Method is Australia, which can be called one huge linguistic area. Many or most Australian linguists believe that all Australian languages belong to a single family, but the evidence is still rather sparse, especially as concerns the northern 'non-Pama-Nyungan' languages (as opposed to the geographically more widespread Pama-Nyungan languages). In trying to account for the murky historical picture in Australia, Dixon has suggested that a "language family may have emanated not from a single language, but from a small areal group of distinct languages, with similar structures and forms" (1997: 98). Australia isn't a good test case for a theory like Dixon's, though. For one thing, the Comparative Method hasn't yet been fully exploited for Australian languages, so we don't yet know how much it will 
contribute to elucidating the histories of all the Australian languages. For another thing, an areal picture that includes extreme structural AND LEXICAL convergence is something unknown elsewhere among the world's Sprachbünde, so Dixon's theory is an appeal to the unknown on the basis of the unknown - namely, on the basis of a situation that isn't at all well understood historically. More substantively, the research in Bowern \& Koch (2004) convincingly refutes Dixon's major claims about Australian historical linguistics.

4.2 ANSWER \#2. The second answer to the question about why the Comparative Method works so well is that the most extreme results of speakers' deliberate decisions are - by all the available evidence - very rare. Secret languages, for instance, are certainly common, but almost all of them are either ephemeral or socially marginal, or both. Only a very few, like Mōkkī, have come into community-wide use and have even become a community's main language.

In a Sprachbund, there are social (not linguistic!) barriers to total amalgamation of the languages over an entire area, and even to total structural amalgamation - namely, in the opposition between the 'other-directed' world view that promotes convergence and the 'self-directed' world view that promotes divergence, or at least maintenance of distinctions (Foley 1986: 27 et passim). It is probable that a speech community that abandons its 'self-directed' world view will shift to a neighbor's language rather than simply continuing to adopt its structure and lexicon until nothing at all is left of the group's original language. (Even in a case like Ma'a, which has borrowed virtually all its grammar and about half of its lexicon from neighboring Bantu languages, about half the vocabulary is maintained as a group-identity symbol.)

Stable bilingual mixed languages like Michif and Mednyj Aleut are also very rare, although, as noted above, ephemeral mixtures of two languages may well be more common. We know that stable bilingual mixed languages are rare because applications of the Comparative Method have so rarely encountered subsystem mismatches that would betray a prior mixing event. There are other kinds of mixed languages too, languages in which the operation of speakers' conscious choices is harder to establish. Gradually evolved mixed languages like Ma'a, whose speakers adopted Bantu features over a period of several hundred years (see $\$ 2.3$ above), pose the same kinds of problems for the Comparative Method as the abrupt mixtures created by bilinguals, and so do the numerous pidgins and creoles around the world: in all these cases, the history of mixture is revealed by subsystem mismatches. Still, the number of languages whose genesis was clearly controlled by speakers' deliberate choices remains tiny.

This means that the Comparative Method is not seriously threatened by the existence of deliberately changed and deliberately created languages: although speakers CAN change their language deliberately and dramatically, they don't usually do so, even in small speech communities. (A case like the Uisai example above, though certainly striking, would not be sufficient by itself to disrupt the operation of the Comparative Method. It could, however, make it difficult or even impossible to trace the history of the gender agreement system.)

4.3 ANSWER \#3. The third answer is that historical linguistics ultimately involves statistical regularities, and is like any science that uses such regularities in having to reconcile macrophenomena with the apparently random behavior of local populations. In economics, for instance, although individuals certainly make their own decisions about (for example) whether to buy a house trailer or a six-bedroom house, macroeconomic theories make predictions over whole populations of consumers (see e.g. Nelson 1984 for discussion of relationships between microeconomics and macroeconomics). In statistical thermodynamics, although both slow and fast particles display random movement, over large spans of time fast particles can be predicted to invade the slow particles' space, providing a justification of the law of entropy (see Callender 1999). In both cases, we have to reconcile the unpredictability of individuals' behavior with the predictability of the behavior of a large population. The closest analogy to historical linguistics, of 
course, is provided by biological evolution, which also is a historical science making use of statistical regularities. Individual members of a breeding population choose their mates in ways that evolutionary theory does not attempt to predict, but statistical principles still apply to a population as a whole (see e.g. Lewontin 1974).

These comparisons with other sciences are relevant to historical linguistics because they highlight the influence of population size on the likelihood of drastic effects resulting from speakers' linguistic choices. Deliberate decision is most likely to affect a single speaker's idiolect and least likely to influence a large group's norm. In other words, speakers' choices are likely to have potentially dramatic effects only in quite small speech communities. The general point is hardly news: as Otto Jespersen observed many years ago (and he was almost certainly not the first to make this observation), "The moving power [for linguistic change] everywhere is an impetus starting from the individual, and...there is a curbing power in the mere fact that language exists not for the individual alone, but for the whole community" (1921: 261).

\title{
5. Conclusion
}

It is still quite possible to find dogmatic assertions in the literature about the impossibility, or at least the extreme improbability, of conscious, deliberate linguistic changes capable of affecting an entire community's language in any significant way. The survey of speakers' choices in this paper points to a different conclusion. First, speakers' choices can indeed lead to drastic linguistic changes. Second, these changes only rarely have a permanent effect on the speech of an entire community; and where they do have a permanent effect, it is because of particular social circumstances. First, the speech community is almost sure to be small. But in addition, there must be other contributing social factors, though not all of them can be identified on the basis of currently available information. One common factor is very widespread multilingualism, with or without socioeconomic dominance by one group in the contact situation, so that the tension between an other-directed world view and a self-directed world view may come into play. Another potential contributing factor, probably less common, is the deliberate actions of language standardizers. A third is the emergence of a new ethnic group that seeks a language to symbolize its new identity.

There are surely other contributing social factors as well, but these are probably a fairly representative sample. It must be emphasized, however, that no contributing factors, no matter how powerful they are in some contexts, will permit us to predict when speakers' choices will produce major changes in a language: contributing social factors are necessary conditions for the kinds of changes under consideration here, but they are not sufficient conditions. Even where small groups live as close neighbors, with very extensive mutual multilingualism, we don't always find widespread structural convergence; whether it occurs or not depends on cultural factors that are likely to remain permanently beyond our predictive grasp.

One further conclusion can be drawn from the robust evidence for potential effects of speakers' deliberate changes in their language. It is still fairly easy to find discussions of 'natural' vs. 'unnatural' change in the literature. Joseph Greenberg, for example, makes the following assertion in an article denying the existence of mixed languages (1999: 632):

\begin{abstract}
It is indeed hard to imagine how a truly mixed language in...the usual sense, could arise by a natural process. Suppose someone had a dictionary and grammar of two quite distinct languages. He or she could then take alternate words and grammatical morphemes first from one and then the other. This would truly be a mixed language but, of course, not arising by any natural process.
\end{abstract}

Greenberg's hypothetical example is more exotic than some of the examples I've surveyed, but not all that much more so than, say, the Mōkkī case. And his very narrow definition of a mixed language - for him, Ma'a is an unmixed Cushitic language in spite of the fact that it now has 
virtually no Cushitic grammar and at least a half-Bantu lexicon! - would probably not attract many fans. But the really interesting point in his statement is his implicit distinction between 'natural' and 'unnatural'. If real speakers of real languages make deliberate changes, are those change processes unnatural? Only if one assumes that unconscious changes alone qualify as natural change. But as I have tried to show, speakers are much more able and willing to manipulate their linguistic resources consciously than they have usually been given credit (or blame) for; and I see no way in which one could establish that this type of linguistic behavior, which is actually quite common in individuals and not vanishingly rare in speech communities, is less natural than unconscious linguistic change.

Finally, although the Comparative Method has worked very well for the great majority of languages around the world to which it has been applied, the method fails, and can in fact be predicted to fail, in cases where speakers' choices do have a drastic effect on a language's lexicon and grammar. Unfortunately for historical linguists' hopes of elucidating language history, such cases can be impossible to unravel retrospectively - except, of course, that we can identify a given language as having had an aberrant history, because the Comparative Method itself alerts us to that fact. Fortunately for our hopes, however, the number of areas in the world where speakers have chosen to make such drastic changes is small, and even within those areas the situation is usually not completely hopeless.

\section{References}

Aikhenvald, Alexandra Y. 1996. Areal diffusion in Northwest Amazonia: the case of Tariana. Anthropological Linguistics 38: 73-116.

Andersen, Henning. 2005. Review article on Brian D. Joseph \& Richard D. Janda (eds.), The handbook of historical linguistics (Malden, MA: Blackwell, 2003). Diachronica 22: 155176.

Bakker, Peter \& Robert A. Papen. 1997. Michif: a mixed language based on Cree and French. Contact languages: a wider perspective ed. by Sarah Thomason, 295-363. Amsterdam: John Benjamins.

Bowern, Claire \& Harold Koch (eds.). 2004. Australian languages: classification and the Comparative Method. Amsterdam: John Benjamins.

Bray, Denys de S. 1913. Census of India, 1911, vol. IV: Baluchistan. Calcutta: Superintendent Government Printing, India.

Callender, Craig. 1999. Reducing thermodynamics to statistical mechanics: the case of entropy. The Journal of Philosophy 96/7: 348-373.

Chomsky, Noam \& Morris Halle. 1968. The sound pattern of English. New York: Harper \& Row.

Dench, Alan. 2001. Descent and diffusion: the complexity of the Pilbara situation. Areal diffusion and genetic inheritance: problems in comparative linguistics ed. by Alexandra Y. Aikhenvald \& Robert M.W. Dixon, 105-133. Oxford: Oxford University Press.

Deumert, Ana. 2005. The unbearable lightness of being bilingual: English-Afrikaans language contact in South Africa. Language Sciences 27: 113-135.

Dixon, Robert M.W. 1997. The rise and fall of languages. Cambridge: Cambridge University Press. 
Dutton, Tom. 1997. Hiri Motu. Contact languages: a wider perspective ed. by Sarah Thomason, 941. Amsterdam: John Benjamins.

Foley, William A. 1986. The Papuan languages of New Guinea. Cambridge: Cambridge University Press.

Grace, George W. 1981. Indirect inheritance and the aberrant Melanesian languages. Studies in Pacific languages in honour of Bruce Biggs ed. by Jim Hollyman and Andrew Pawley, 255268. Auckland: Linguistic Society of New Zealand.

Grace, George W. 1990. The "aberrant" (vs. "exemplary”) Melanesian languages. Linguistic change and reconstruction methodology ed. by Philip Baldi, 155-173. Berlin: Mouton de Gruyter.

Grace, George W. 1996. Regularity of change in what? The comparative method reviewed: regularity and irregularity in language change ed. by In Mark Durie \& Malcolm Ross, 157179. Oxford: Oxford University Press.

Greenberg, Joseph H. 1999. Are there mixed languages? Poetika, istorija, literatury, lingvistika: sbornik k 70-letiju Vjac, eslava Vsevolodovic, a Ivanova ed. by A.A. Vigasin \& al., 626633. Moscow: OGI.

Heath, Jeffrey. 1989. From code-switching to borrowing: a case study of Moroccan Arabic. London: Kegan Paul International.

Jameson, J.Franklin (ed.). 1909. Narratives of New Netherland: 1609-1664. New York: Scribner.

Jespersen, Otto. 1921. Language: its nature, development, and origin. London: George Allen \& Unwin Ltd.

Kinkade, M. Dale. 1995. Transmontane lexical borrowing in Salish. In: Papers for the $30^{\text {th }}$ International Conference on Salish and Neighbouring Languages, 28-46. Victoria, BC: University of Victoria.

Kroskrity, Paul. 1993. Language, history, and identity: ethnolinguistic studies of the Arizona Tewa. Tucson: University of Arizona Press.

Kulick, Don. 1992. Language shift and cultural reproduction: Socialization, self, and syncretism in a Papua New Guinean village. Cambridge: Cambridge University Press.

Labov, William. 1994. Principles of linguistic change. Volume I. Oxford: Blackwell.

Lass, Roger. 1997. Historical linguistics and language change. Cambridge: Cambridge University Press.

Laycock, Donald C. 1982. Melanesian linguistic diversity: a Melanesian choice? Melanesia: beyond diversity ed. by Ron J. May and Hank Nelson, 33-38. Canberra: Australian National University Press.

Lewontin, Richard C. 1974. The genetic basis of evolutionary change. New York: Columbia University Press.

Li, Paul Jen-Kuei. 1980. Men's and women's speech in Mayrinax. In : Papers in honor of Professor Lin Yü-k'eng on her seventieth birthday, 9-17. 
Li, Paul Jen-Kuei. 1982. Male and female forms of speech in Atayal. The Bulletin of the Institute of History and Philology, Academia Sinica, vol. 53, part 2. Taipei, ROC.

Lightfoot, David W. 1979. Principles of Diachronic Syntax. Cambridge: Cambridge University Press.

Lightfoot, David W. 2002. Myths and the prehistory of grammar. Journal of Linguistics 38: 113136.

Lindeström, Peter. 1925. Geographia Americae with an account of the Delaware Indians; based on surveys and notes made in 1654-56. Translated by Amandus Johnson. Philadelphia: The Swedish Colonial Society.

Lydall, Jean. 1976. Hamer. The non-Semitic languages of Ethiopia ed. by Lionel M. Bender, 393438. East Lansing, MI: African Studies Center.

Mous, Maarten. 1994. Ma'a or Mbugu. Mixed Languages ed. by Peter Bakker \& Maarten Mous, 175-200. Amsterdam: Institute for Functional Research into Language and Language Use (IFOTT).

Müller, Max. 1861. Lectures on the Science of Language. London: Longman, Green, Longman \& Roberts.

Muuk, E. 1940. Väike õigekeelsus-sõnaraamat ['Small orthological dictionary']. $7^{\text {th }}$ edn. Tartu.

Nelson, Alan. 1984. Some issues surrounding the reduction of macroeconomics to microeconomics. Philosophy of Science 51: 573-594.

Norman, Jerry. 1988. Chinese. Cambridge: Cambridge University Press.

Oksaar, Els. 1972. Bilingualism. Current trends in linguistics, vol. 9: Linguistics in western Europe ed. by Thomas A. Sebeok, 476-511. The Hague: Mouton.

Pargman, Sheri. 1998. On the regularity of hypercorrection in phonological change. Diachronica 15: 285-307.

Pharris, Nicholas \& Sarah G. Thomason. 2005. Lexical transfer between Southern Interior Salish and Molalla-Sahaptian. Papers for the $40^{\text {th }}$ International Conference on Salish and Neighboring Languages (Vancouver), 184-209.

Romaine, Suzanne. 1996. The status of sociological models and categories in explaining language variation. Toward a critical sociolinguistics ed. by Rajendra Singh. Amsterdam: John Benjamins. [Reprinted from Linguistische Berichte 90: 25-80, 1984.]

Ross, Malcolm \& Mark Durie. 1996. Introduction. The comparative method reviewed: regularity and irregularity in language change ed. by Mark Durie \& Malcolm Ross, 3-38. Oxford: Oxford University Press.

Saagpakk, Paul F. 1982. Estonian-English dictionary (Introduction, section 'Linguistic innovation in Estonian’, pp. Lxxix-Lxxxvii). New Haven: Yale University Press.

Sapir, Edward. 1921. Language: an introduction to the study of speech. New York: Harcourt, Brace \& World. 
Stone, Gerald L. 2003. The lexicon and sociolinguistic codes of the working-class Afrikaansspeaking Cape Peninsula coloured community. Language in South Africa ed. by Rajend Mesthrie, 381-397. Cambridge: Cambridge University Press.

Suttles, Wayne. 1965. Multiple phonologic correspondences in two adjacent Salish languages and their implications. Paper presented at the $18^{\text {th }}$ Northwest Anthropological Conference, Bellingham, WA, April 1965.

Tarpent, Marie-Lucie. 1987. Between ergative and accusative syntax: lessons from Nisgha/English syntactic interference. Papers from the $22^{\text {nd }}$ International Conference on Salish and Neighboring Languages ed. by John Dunn, 149-171.

Thomason, Sarah G. 1995. Language mixture: Ordinary processes, extraordinary results. Spanish in four continents: Studies in language contact and bilingualism ed. by Carmen SilvaCorvalán, 15-33. Washington, DC: Georgetown University Press.

Thomason, Sarah G. 1997. On mechanisms of interference. Language and its ecology: Essays in memory of Einar Haugen ed. by Stig Eliasson and Ernst Håkon Jahr, 181-207. Berlin: de Gruyter.

Thomason, Sarah G. 2000. On the unpredictability of contact effects. Estudios de Sociolingüistica 1.1: $173-182$.

Thomason, Sarah G. 2001. Language Contact. An Introduction. Edimburgh: Edimburgh University. Press.

Winter, Werner. 1992. Borrowing and non-borrowing in Walapai. Language contact: theoretical and empirical studies ed. by Ernst Håkon Jahr, 213-228. Berlin: Mouton de Gruyter.

Wright, Roger. 1998. Untitled post in the thread 'Cladistic language concepts' on the HISTLING list. 